\title{
RECONSTRUCTING LEWIS CARROLL'S LOOKING GLASS
}

Jonathan Hansen

\section{Introduction}

Lewis Carroll poses to the modern reader no simple persona. Charles Lutwidge Dodgson (Lewis Carroll's given name) ${ }^{1}$ was a reverend, a mathematician, a photographer and a writer, in descending order of importance to his own self-image. Above all these, however, he was a lover of children - more specifically, of little girls; he befriended them (with far more ease than he befriended adults), wrote to them (at great length), photographed them (nude, preferably), composed poetry and longer works of literature for them and generally adored them.

It is this last and most significant preoccupation with children that is most troubling to modern readers of Carroll. Modern readings of Carroll offer many different ways to deal with this seemingly anomalous aspect of an ostensibly pious man.

Dodgson's love of children is seen by many as pure and harmless in its motivations - even as a barometer of Victorian Romantic notions of the Rousseauian child as a sexless and innocent creature, a creature closer to God than adults. Dodgson himself penned many words that are used to support this view, such as these in a letter to Mrs. C. F. Moberly Bell, the mother of one of his child-friends, dated September 27, 1893:

It is very healthy and helpful to one's own spiritual life: and humbling too, to come into contact with souls so much purer, and nearer to God, than one feels oneself to be. (Letters, v.II, 980)

Such sentiments are echoed by Dodgson's most prolific biographer, Morton Cohen. Never failing to defend Dodgson's character, Cohen boldly bottom-lines the debate in statements such as this:

The truth is that he loved much and many, and his love helped a succession of young people find their footing in life and grow up happier and more self-confident than they might have done had he not 
trod this earth. (Morton 19)

To others, however, Dodgson's interests are suspicious, even prurient. Such readers would place Dodgson in a Victorian context closer to the one presented by scholar Steven Marcus. In The Other Victorians, Marcus exposes the abundance of underground child pornography and child-prostitution in Victorian England. Dodgson's own words can be invoked to support this view as well, as they often sound (to a post-Freudian audience, at any rate) disturbingly eroticized, such as in the closing of this letter sent to Dodgson's (adult) friend Gertrude Thomson, dated August 10, 1897:

Haven't you got your little camera with you? And could you not make friends with some of these girl-fairies, and do me a photo of one, or of a group, with a background of rocks? And, if you chance to make friends with any exceptionally nice little nudity (no matter whether she is beautiful or not: only nice ones will do) who is willing to be victimized for my benefit, I will send you a book to give her. (Letters, v. II, 1135, his emphasis)

Even if one grants that Dodgson's rhetoric of power and victimization may be merely in jest, such a comment serves, at the very least, as a remarkable recognition of the potential perception of his motives as basically immoral. And if one imagines Dodgson's motives as unseemly, then it is particularly unnerving that he suggests using his persona as Lewis Carroll, trusted author of children's literature and just lover of children, as a bargaining tool in a sexual marketplace.

But to prove conclusively whether Charles Dodgson was a child-lover of saintly or perverse motive is not the goal of this paper. Such a goal may very well be impossible to achieve, and its merit, ultimately, questionable. The necessary distinctions are largely subjective: some view Dodgson's nude child photography as pornographic, and others view it as artistic. And as these images are bound up in particular historical and social contexts, modern observations rarely escape anachronism. Even reconstructing the reception of such images in Victorian England is a matter of comparing the subjective and widely varying viewpoints of different Victorians.

Instead of attempting such speculations, I ask, what are the current influences that guide our reading of Dodgson/Carroll and his literature? How do we deal with the tenuous boundaries established and subsequently traversed both in his literature and his life? What is at stake in characterizing Dodgson as a pedophile, and how does that reflect upon (and affect) our current situation? In considering these questions, we are not simply defending or debasing literary figures of the past; these questions are basically linked to the various ways we understand literature and history, as well as the controversy surrounding childlovers of our contemporary culture.

\section{The Politics of Mirrors}

The contradictions Dodgson poses reflect the duplicity of the fictional world presented to readers through the theme of mirror images in Lewis Carroll's Alice books. Mirror images are both the same and not the same, as 
they are duplicates of one another - but inverted. Wonderland is the mirror of reality (a relationship made quite literal in the second book of the series, Through the Looking Glass); the difference of Wonderland marks clearly where reality is not, thereby signifying both fantasy and reality at once.

The mirror relationship of fantasy to reality in Wonderland has been classically understood as one that ratifies the Victorian view of reality; fantasy is clearly marked off and relegated to the fantasy world. The fantasy world is a pleasant excursion, but is ultimately subordinate to the real world, which serves as the narrative frame in both of the Alice books. Furthermore, the fantasy is fanciful precisely because of its inversion of the real world; it can only be understood as illogical because logic is both real and absent in Wonderland. The relative stability of the Victorian social order, then, is present through absence in Wonderland.

This Victorian "real world" is the world of logic and mathematics in which Dodgson lived an orderly life of monotheistic religion and university education. As Walter E. Houghton states in The Victorian Frame of Mind, it is a world with "faith in the existence of ultimate truths...and in the capacity of the human mind to discover them by some form of reason or of intuition" (14). Author Jackie Wullschläger, in her book Inventing Wonderland, speaks of this Victorian reality as "....an age that was more innocent, happy to accept absolute values, less knowing and cynical and relativistic than our own" (204). In this paradigm, no intermingling of this resolutely real world with the nonsense of Wonderland could be sanctioned. Carroll's Alice books, it is often argued, demonstrate this sensibility both formally - by the framing narratives - and diegetically - by the clearly established boundaries of either the rabbit hole or the surface of a mirror.

Victorian reception of Alice's Adventures in Wonderland seems to reflect this construction of fantasy as separate and subordinate to reality, if the following book review from The Sutherland Herald provides any indication:

This pretty and funny book ought to become a great favourite with children. It has this advantage, that it has no moral, and that it does not teach anything. It is, in fact, pure sugar throughout. (Wullschläger 54) The reviewer seems to find pleasure in the distance from reality that Wonderland maintains through these narrative boundaries. Wonderland is understood to be a lack of moral, a lack of logical reality that leaves reality intact and even strengthened through the brief, inoculating dip into nonsense.

In her book Reflections of Fantasy, Beverly Lyons Clark makes this point by contrasting Carroll with two fantasy fiction writers of the 20th century, Vladimir Nabokov and Thomas Pynchon, both of whom blur the border between fantasy and reality in a manner that is directly counter to Victorian sensibilities. For example, the sexual fantasies of Lolita's loquacious narrator, Humbert Humbert, do not remain diversions into nonsense; they have real and dramatic effects on the reality experienced by himself and others, fundamentally destabilizing several familial and social relations. Furthermore, the structure of Lolita complicates the distinction between real events and the fantasies of Humbert, 
forcing the reader to question the narrator's reliability. Despite all of the nonsense and confusion in Wonderland, the voice of Carroll, himself narrating the Alice books, remains comparatively stable.

These different approaches to fantasy effectively illustrate some ways in which the modern period of the late 19th and early 20 th centuries can be perceived as distinct from the postmodern period of the late 20 th century. The former is characterized, in part, by a basic investment in the Cartesian split between mind and body, between interior and exterior existence, and the taxonomic knowability of the exterior world. The latter, however, is critically skeptical of this kind of positivism and lacking in any "faith in the existence of ultimate truths." So the challenge to the hierarchal separation of fantasy and reality demonstrated by comparing Nabokov's novel to Carroll's is representative of a more general postmodern challenge to the hierarchal separation of subjective and objective experience. This intellectual drift is the result of a constellation of social, political, economic, technological and philosophic changes. A few of those changes that are most pertinent to the argument at hand include: de-colonization and the fall of imperialism; civil rights legislation and government protection of minority groups (especially, as will be discussed below, the rights of children); the chemical revolution and the rise of the pharmaceutical industry; and Freudian thought, which collapses Cartesian dualism by demonstrating that the interior of the mind is manifested in the body, leading eventually to modern psychiatric practice.

Clark reads Carroll's fiction in terms of Victorian positivism, but to the ultimate end of contrasting it with $20^{\text {th }}$ century, postmodern fantasy fiction. For Clark, Carroll functions as the embodiment of the imperial world against which postmodern fiction reacts. In this way, Clark maintains a rather traditional interpretation of Carroll's work while still embracing the critical insights of postmodernism.

Most other postmodern Carroll scholarship, however, tends to deconstruct the very tenants of positivism upon which traditional readings of Carroll's work are based. Thus, what Wullschläger and others view as an "age of innocence" is viewed in more critical terms. Far from innocent, this is an age and a culture actively involved in imperialist, economic, religious, racial and sexual oppression. The apparently scientific and objective truth of social Darwinism, for example, is now understood as the exceedingly ethnocentric and subjective position of a ruling minority who achieved consensus through the marginalization of dissent. In this light, "ignorance," rather than "innocence," is perhaps a more appropriate title for the age.

In fact, these two words were closely linked in the practice of raising children in Victorian England. Innocence, the quality most dearly associated with the child (especially the girl child) was insured through forced ignorance. Rousseau's view of childhood as a pure and natural state, inevitably corrupted by education, was a widely influential model. In its uniquely Victorian inflection, this resulted in the careful withholding of education - particularly on the subjects of sex and the body, and particularly, again, with girls. This repression 
of information for the sake of "innocence" led to instances such as this one, recounted by Naomi Mitchison, who grew up an upper-middle class girl in Oxford towards the end of the Victorian era:

I was twelve, still at the Dragon School unsuspecting. I had little or no pubic hair, my breasts were ungrown and did not in fact develop until my mid-teens. And then there was blood on my blue serge knickers. I was quickly pulled out of school and I never went back. I couldn't quite understand why, only it seemed that it was something about me which was shameful and must above all never be mentioned to a school friend. It had been a complete surprise, because I had not taken in my mother's carefully veiled and no doubt physiologically inaccurate information. The process was not at all well-known at that time, and there were many superstitions about it and little medical help...For many years I had monthly pain, distress and acute embarrassment; I was taken to various doctors, but, as nobody understood the physiological process, this did not help. The curse, as it was always called, was a main trouble all my life. (Dyhouse 21-22, emphasis added)

In light of such a recollection, it is not surprising that Alice wonders at the uncontrollable whims of her own body, or that when questioned by a bird in the fifth chapter of Alice's Adventures in Wonderland, she can hardly respond with any conviction as to just what exactly she is.

These bodily concerns seem to have been just as confusing and frustrating to Dodgson himself, judging by his greater ease with "simpler" folk (a term by which Dodgson meant pre-pubescent children) with whom such issues would hardly be discussed. This can be perceived in comments such as this one, an excerpt from a diary entry dated May 11, 1865, one week after the thirteenth birthday of Dodgson's most favorite girl-child, Alice Pleasance Liddell:

Met Alice and Miss Prickett in the quadrangle: Alice seems changed a good deal, and hardly for the better - probably going through the usual awkward stage of transition. (Clarke 112)

The interpretive strategy demonstrated in the above paragraphs positing that Alice's experiences in Wonderland may have direct connection to the feelings of Victorian girls and of Dodgson himself - is typical of both popular readings and academic scholarship of Carroll/Dodgson in its attempt to erase the boundary between fantasy and reality established in Carroll's writing. The desire to collapse this dualism - and thereby reject the "objective truth" of imperial Victorian culture - has influenced not only fiction of the 20th century, but also critical approaches to understanding Victorian literature and Dodgson. This is achieved largely outside of the text, effectively eschewing New Criticism and close reading approaches to understanding literature in the process. Instead, contemporary readers tend to look at what is behind the letter of the text; to peek into the wings of the social stage; and finally, to examine the personal life of Charles Dodgson. It is this drive to conflate fantasy and reality through extratextual criticism that I am examining, and it is the modern re-constructions of 
Dodgson - and the social function that those constructions perform - that I find fascinating.

\section{Text}

Classically, textual analysis has been used to interpret the Alice texts in accordance with a Victorian paradigm. More recently, extratextual evidence has been employed as a means of distancing the reader from that positivist project. From this, however, one should not mistakingly conflate textual analysis with Victorian or colonial ideals. Neither is one limited to Beverly Lyons Clark's model of textual analysis, in which Carroll's ultimate rationality is maintained as a foil to set off the more sophisticated ambiguities of postmodern fiction. Perhaps the salacious nature of the speculations on Dodgson's private life lead readers, like siren song, away from the text; however, the text itself has not been exhausted of details that complicate the fantasy/reality dichotomy. These quiet voices of dissent have been, as would be expected, marginalized. Nonetheless, close reading alone may bring some of them out.

For example, it is remarkable that there has been, to my knowledge, no sufficient critical attention paid to the closing poem of Through the Looking Glass:

A boat, beneath a sunny summer sky

Lingering onward dreamily

In an evening of July

Children three that nestle near,

Eager eye and willing ear,

Pleased a simple tale to hear -

Long has paled that sunny sky:

Echoes fade and memories die:

Autumn frosts have slain July.

Still she haunts me, phantomwise

Alice moving under skies

Never seen by waking eyes.

Children, yet the tale to hear

Eager eye and willing ear,

Lovingly shall nestle near.

In a Wonderland they lie,

Dreaming as the days go by,

Dreaming as the summers die.

Ever drifting down the stream - 
Lingering in the golden gleam -

Life, what is it but a dream?

These stanzas relate the genesis of the Alice project. Alice's Adventures in Wonderland is the consolidation of several stories extemporaneously composed by Dodgson for the entertainment of his young companions while in the course of an outing. Principle among these children was Alice Pleasance Liddell (18521934), Dodgson's most treasured of all acquaintances and the inspiration of the Alice character in his books. Her full name can be seen in this poem by reading, vertically, the first letter of each line.

While Wonderland may have been effectively contained within the narrative frame of rationality, this closing poem of the second book perniciously pokes a hole in that frame, intertwining the dream narrative - the very device used to contain the nonsensical events of the book - with Carroll's own biography. In so doing, the final line of the poem suggests that reality is a fanciful and capricious construction, as the dream narrative has been a fanciful and capricious construction. The converse of this is suggested in lines 10-12: that perhaps the "real" experience of Dodgson's memory, the love of a child that inspired the very poem, was only ever whimsical dream, a fantasy. While Alice's awakening from the dream as the final event of the framing narrative may contain Wonderland within the confines of rationality, this poem as an epilogue brings an element of question back just before the closing of the book, and complicates the situation. The author acknowledges the power that the fantasy actually holds over the framing reality by placing an element of that fantasy outside of the frame. Carroll also, in this poem, explicitly connects his work of fiction to a factual moment (the work of fiction's pre-history) and a real person (Alice Liddell).

Close readings of Carroll's texts to this end are less common than other strategies. More often, readers look for bridges between fantasy and reality that are conspicuously missing from the text, essentially fabricating events that explain the nonsense of Wonderland. These explanations may be based on textual events, but take advantage of the lack of detail or explanation surrounding those events. A typical example from popular culture is the song "White Rabbit", written by Grace Slick and performed by the now defunct rock group Jefferson Airplane. The bulk of the lyrical content consists of imagery drawn directly from the Alice books; however, Slick offers her own explanation for the fantasy vision.

One pill makes you larger

And one pill makes you small.

And the ones that mother gives you

don't do anything at all.

Go ask Alice

when she's ten feet tall. 
And if you go chasing rabbits

And you know you're going to fall,

Tell 'em a hooka-smokin' caterpillar

has given you the call.

Call Alice

when she was just small.

When men on the chessboard

get up and tell you where to go.

And you've just had some kind of mushroom,

and your mind is moving low,

Go ask Alice

I think she'll know.

When logic and proportion

have fallen sloppy dead,

And the White Knight is talking backwards,

and the Red Queen's lost her head,

Remember what the Dormouse said:

Feed your head,

feed your head. (Phillips, 419-420)

It is hardly likely that, in Carroll's work, the Dormouse was suggesting the use of psychedelic drugs to Alice — but that is not what is really at stake. The notion that Carroll used psychedelic drugs in the composition of his works, and, moreover, that he encodes psychedelic drug use in his stories, is such a widely held belief that many refuse to be convinced otherwise. Despite the uncanny mycological coincidences, however, there is simply no evidence whatsoever in diaries, letters or personal accounts to suggest that Dodgson used any kind of drugs to spark his creativity. In fact, the unfailing reports of his temperance make the suggestion even less plausible.

The idea that visions of the Wonderland ilk are part and parcel of hallucinogenic experience is, in fact, an inherently modern one. While hallucinogenic plants of many varieties have indeed grown naturally throughout history, the effects of their ingestion were known to very few Europeans in the $19^{\text {th }}$ century. What reports exist in print from this time are limited to botanical and scientific journals. ${ }^{2}$ Perhaps Dodgson had come across some of these reports, but it is unlikely that he took psychedelic investigation any further than this. In this context, obtaining and ingesting hallucinogenic materials would have been anything but a casual event for Dodgson, requiring a remarkable amount of research, and making it even less likely that he would neglect to journal such experimentation.

It is interesting to note, however, that Sir John Tenniel's illustration of the caterpillar on his mushroom throne depicts with a significant degree of accuracy a hallucinogenic species of fungus, the fly agaric mushroom. So if 
there was an amateur mycologist involved in the Alice project, perhaps it was Tenniel, rather than Dodgson. But this is only wild speculation, worth, at most, some further inquiry. Tenniel may just as well have stumbled coincidentally upon the physical qualities of the fly agaric mushroom, or may have been similarly informed of it through esoteric botanical literature.

The obstinate conviction that Dodgson was on drugs reveals more about the modern mind-set than it does Dodgson's. The idea that visionary experiences may be induced somatically (with psychoactive chemicals, for example) did not become widely accepted until after the laboratory discovery of LSD and its popular boom in the ' 60 's. Previous to the isolation and mass production of such powerful chemicals, subjective states of consciousness were far less malleable in material terms. Somatic control of consciousness, while not commonly experienced by most people, is now a commonplace concept commonplace enough that it is the first conclusion many people jump to when faced with realities as deviant from the norm as Wonderland.

The association of hallucinogenic drugs and Alice in Wonderland was only made stronger by the fact that the LSD culture of the ' 60 's quickly adopted Alice as a "guidebook" through a hallucinogenic trip. This is what can be seen in exploitation movies such as Alice in Acidland, as well Jefferson Airplane's "White Rabbit." In this sense, it can be clarified that Carroll's vision of Wonderland may not necessarily look so much like an acid trip. Rather, it's the other way around; what has come to be understood as the visual markers of an acid trip were originally influenced by Carroll's fiction. And what this demonstrates for the argument at hand is the popular imperative to make sense of the breach between fantasy and reality in Carroll's fiction, even at the cost of historical inaccuracy and textual re-writing.

But the most extreme example of textual re-writing I have discovered proves that literary junkies can be far more whacked out than any member of the drug culture. Richard Wallace, in his book The Agony of Lewis Carroll, suggests that the problematic schism is a manifestation of Dodgson's repressed, secret life of homosexual, pedophilic, sadomasochistic and even bestial desires. Wallace asserts this by claiming that Dodgson coded messages to this effect in his children's books. These messages have been coded, apparently, through anagrams (the rearranging of letters to create new words and meanings) that Wallace "solves."

For example, the opening lines of the poem "Jabberwocky," which appears in Through the Looking Glass, read in the original text as follows:

Twas brillig, and the slithy toves

Did gyre and gimble in the wabe:

All mimsy were the borogroves,

And the mome raths outgrabe.

Wallace, however, rearranges the letters of this stanza to reveal its secret meaning:

Bet I beat my glands til,

With hand-sword I slay the evil gender. 
A slimey theme; borrow gloves,

And masturbate the hog more! (59)

Similarly, from the seemingly innocent title of a seemingly innocent article attacking cruelty to animals which Carroll wrote and published on June 1, 1875, in the Fortnightly Review - "Some Popular Fallacies About Vivisection" Wallace rearranges the letters and decodes the secret message Dodgson apparently authored as, "I crave lamb coitus, save up fellatio poison" (34). This and many other "deciphered" anagrams, coupled with textual incidents of affection towards animals in the Alice books, make up the main part of Wallace's argument. If this wasn't enough, Wallace wrote a second book, Jack the Ripper: "Light-hearted Friend", in which he uses more of the same shaky evidence to suggest that Lewis Carroll was directly responsible for the murder and disembowelment of several London prostitutes attributed to the mysterious and never apprehended Jack the Ripper.

I hope that the fallacy of Wallace's logic is apparent: "solving" anagrams is a creative process, not a deductive one, and the results reflect the solver's intentions more than the original author's. This can be illustrated by my own "discovery" that The Agony of Lewis Carroll, when anagrammed, reveals the "true" message of Wallace: Note: Lie or Goofy Scrawl. Ha! An extremely generous reader might go so far as to attribute this mischievous meaning to Wallace, since his argument does, in fact, sound ridiculous enough to be a highly involved joke. However, Wallace's writing lacks any of the grace or humor that might lead me to be that generous, and his overwrought conviction is ultimately only demonstrative of what increasingly appears to be a need to uncover the hidden link between fantasy (of Lewis Carroll) and reality (of Dodgson).

\section{Context}

The presence of contemporary social and cultural issues in Carroll's text may also rectify the disjuncture between fantasy and reality. For example, one can read growing concern with the ideas of Darwinism present in Alice's Adventures in Wonderland in the image of the sea of tears, from which emerge Alice and an array of other creatures at various stages of the evolutionary process. The presence of a Dodo bird, an evolutionary museum piece, seems to further identify the sea of tears as the salty primordial sea giving rise to all life forms, even those now extinct. This is potentially scandalous, as Alice is shown emerging from the very same sea, erasing the fundamental difference between man and animal, which is one of the basic tenants upon which Victorian Protestant religion is based. This notion comes up again later, in a morbid scene of inverted evolution in which a human baby transforms into a pig. Perhaps Carroll is lambasting such notions by locating them in Wonderland, a place of no logic or science. However, regardless of the political intent of the author, 21 st century readers can enlist the simple presence of these images to defend the association of real social concerns with a text classically interpreted as "pure sugar."

Also resonant with the text are concerns of increasing social mobility and loss of class security in a newly capitalist society. From the leisure afforded 
to Alice and her sister in the opening of the framing narrative, Alice is already marked as middling-to-upper class, and she expresses fears of losing class status in the second chapter of Alice's Adventures in Wonderland.

...her eyes filled with tears again as she went on, "I must be Mabel after all, and I shall have to go and live in that poky little house, and have next to no toys to play with...

Conversely, we later see Alice change into a queen merely by leaping over a brook. Class standing is certainly tenuous and constantly in flux in Wonderland.

Also, the Queen of Hearts is often seen as a parody of Queen Victoria in all of her mannerisms. This parody relies as much on the illustrations of Sir John Tenniel as it does Carroll's characterization. Tenniel was a popular caricaturist for the magazine Punch, which suggests that Carroll may have consciously invited such lampooning into the project when he chose his illustrator. Through Tenniel's hand, the public as well may have received such depictions as political satire.

Acknowledging this frustrates the established split between fantasy and reality as it has classically been viewed in Carroll's work. This kind of satire relies on the reader bringing knowledge of the real into the fantasy world. In other textual instances, the presence of rationality in Wonderland ultimately serves to underscore the nonsense of the fantasy through contrast - such as Alice's attempt to apply table manners to the Mad Hatter's tea party, or her unsuccessful attempts to calm herself by reciting mathematics and nursery rhymes. In this case, however, aspects of the real world (for example, the dour matriarch Queen Victoria), intimated visually as much as narratively, are remarkable for their similarity to Wonderland, not their difference. Furthermore, while in the previous cases reality is invoked in order to quantify the degree of nonsense in Wonderland, in parody and social commentary the goal is insight into the real world, thereby inverting and altogether blurring the borders of fantasy and reality.

\section{The Man Behind the Text}

The border between public and private life is one that Dodgson fought vehemently in his lifetime to maintain. Charles Dodgson would not answer to the name of Lewis Carroll in interview or conversation; he refused to give out any photographs; he returned, unopened, any mail which was addressed to Lewis Carroll; and even to his child-friends he posed as merely a good friend of Lewis Carroll, insisting that they call him Charles Dodgson. In a letter to his friend and fellow poet Francis H. Atkinson, Dodgson refers to himself as one who, having been unlucky enough to perpetrate two small books for children, has been bullied ever since by the herd of lion-hunters who seek to drag him out of the privacy he hoped an "anonym" would give him. I have really had much persecution of that sort... and I so much hate the idea of strangers being able to know me by sight... (Letters $v$. I, 445-446)

But Dodgson's feelings on the matter fail to keep the public out. Even 
the most basic knowledge of Dodgson's life and his relationship with Alice Liddell and other child-friends makes it almost irresistible to read these relationships into the text. There are many popular assumptions regarding Dodgson's presence in the text, one of the most common being that the White Knight in Through the Looking Glass is a stand-in for Dodgson himself. There are several points of similarity: the White Knight is socially clumsy, as Dodgson was often quite shy in public and had a dramatic speech impediment; the Knight is shown to be eternally inventive, while Dodgson, even beyond the creativity of the Alice books, was constantly making puzzles, games and useful household items; the Knight is perceived as elderly (again, as a result of Tenniel's illustration rather than any textual reference to age); and the Knight is ultimately a quixotic, absurdly kind-hearted gentleman who knows full well that he must soon let Alice go to become a queen. It would be enough to accept becoming a queen as a metaphor for Alice's leap to womanhood, but, as it happens, Alice Liddell was actually courted for a time by Prince Leopold, who was attending Oxford. The courtship, which was somewhat doomed from the start and was never realized, was kept quiet; one can imagine, however, that if ever there were an observant and jealous watcher from afar, Dodgson would be that watcher of Alice and her suitors.

Delving further into the personal affairs of Dodgson requires a good deal of invention and induction, alternately.

Dodgson was a meticulous recorder of every activity and thought in his diaries; he carefully filed all of his photographic prints, and he even kept a record of all the letters he wrote and received. Despite these careful journaling efforts, however, much important information has been irretrievably lost. This was largely due to a systematic purging of many of Dodgson's personal belongings and writings upon his death. Some of the items, for example hundreds of his photographs of nude girls, were destroyed according to the request of Dodgson upon the occasion of his death. Other things, such as Dodgson's diary, were altered by another hand, presumably some member of the family.

Of particular interest is the account of June 27, 1863, which was removed and the pages adjacent rewritten by another hand in an attempt to hide the alteration. ${ }^{3}$ Prior to this day, Dodgson was spending a great deal of time with Alice Liddell, and often alone. After this day, only a handful of brief meetings with Alice Liddell are ever again mentioned in his life, and none of them are alone. Dodgson does mention on several occasions trying to appeal to Alice's mother for more solitary meetings with her daughter, but none of these appeals appeared to work. For what conspicuously unmentioned indiscretion could Dodgson be appealing to Mrs. Liddell? What happened on this missing day that drove Dodgson apart from the one girl-child he loved more than any other for the rest of his life? Where might that incident, whatever it may be, be coded into the text of the Alice books? Such speculation can really prove very little. It does, however, satisfy many readers' desires for the convergence of fantasy and reality, and in doing that, demystifies the great "age of innocence" at the site of one of its exemplary "innocent" authors. 
But the element of Dodgson's personal life that has most captured and repelled readers is his photographing of nude girls. This is yet another mirror that Dodgson puts in front of us; the Reverend Charles Dodgson and the photographer are both one in the same, yet seem so contrary to one another, to the best reasoning of our sensibilities. All of Dodgson's photographs are artful; there is no doubt that he was certainly a pioneer in the new field. Equally undeniable, however, is the fact that a good number of the photographs present themselves to the 21 st century viewer as overtly sexual. "The Portrait of Evelyn Hatch", in which the child is sprawled out, naked and coquettish, may be the most blatant example of this. But even the more subtle portraits, such as "Alice Liddell as a Beggar," contain a latent sexuality in the careful exposure of the shoulder and, through peasant dress, the fetishization of the lower classes, who were seen at the time as being more sexually "loose." The heightened potential sexuality of this state of partial undress was evident to Dodgson himself, as implicated in his letter to Mrs. P.A.W. Henderson, dated July 12, 1879:

When children who know me well, and who regard dress as a matter of indifference, I am very glad (when mothers permit) to take them in any amount of undress which is presentable, or even in none (which is more presentable than many forms of undress)... (Letters, v. I, 346)

The sexuality of the portraits is hardly a point of discussion. The question that the sexuality of these photos raises is: in what climate could these photos be taken? Morton Cohen, in his essay "Lewis Carroll and Victorian Morality," would have us believe that such images are

not all that exceptional. Anyone who works with Victorian illustrated books is accustomed to encountering frequently drawings and paintings of unclothed, sexless children. It is simply another offshoot of the cult of worshipping childhood innocence. (16)

Other scholars, however, paint a very different portrait of the period. In an essay entitled "The Look of Little Girls: John Everett Millais and the Victorian Art Market," Leslie Williams describes a Victorian marketplace exchanging images of young girls, many of which are subtly but undeniably charged with a sexual energy, unlike Cohen's "sexless children." Mark Spilka, in his essay "Dicken's View on Childhood," points out that very young girls were in such high demand as prostitutes that "grown prostitutes began to dress like them to recapture the trade" (175).

Cohen also insists that mothers flocked to Dodgson and gave him their consent to have their daughters photographed in the nude without exception. A review of the letters written to these mothers, however, reveals a great many letters in which Dodgson bickers with the mothers, bargaining with them to let their children come without chaperone and without clothing. A good deal of snobbish letters are sent to mothers who flat out refuse Dodgson's requests, as well. This letter, to Mrs. J. Chataway, dated November 1, 1876, is but one of many supplicant letters to apparently outraged mothers:

You speak of "erasing a negative" with a calmness which a photogra- 
pher would not share with regard to any of his artistic offspring. A good negative is to a photographer (at least in my case it is) as valuable, artistically, as a print: and it has the advantage of not fading, which prints nearly always do. So I hope at least you will be in no hurry to have the negative (I mean the good one of the 3 in bathing-drawers: the other 2 I will erase forthwith) destroyed. It is locked up safe, where no printer can get at it: and it is entered on a list "to be erased," as a direction to my Executors, when the negatives come into their possession. (Letters, v. I, 262)

This single letter raises some intriguing questions. If the " 3 in bathing-drawers" are the "good" negatives, what implicitly bad ones aren't even mentioned? Is this evaluation only one of professional quality, or is it an ethical "bad" and "good" that Dodgson employs? Why does Dodgson plead to hold on to the negatives, but concede to have them destroyed at a later time? What pleasure did he want to preserve for himself that he did not want to persist after his death? Such requests to erase negatives and burn prints were apparently carried out by Dodgson's executors, and one can only imagine what photos were lost.

As authors such as Spilka and Marcus demonstrate, there is substantial evidence that the sexuality of children was a part of the cultural understanding of many Victorians. I would suggest then, that it was not, as is intimated by Cohen, the inherent innocence of the age which allowed mothers to consent to Dodgson's photography in good conscience, but rather the same polarized construction of fantasy and reality we have already seen at play in Carroll's fiction and its popular reception. Any recognized sexuality of the girl-children was contained within the fantasy of the photos, and would therefore not be perceived as intermingling with reality any more than Wonderland could come up the rabbit hole and disturb the secure position of middle-to-upper-class Victorians. The fantasy element is maximized in Dodgson's photographs, a fact which further lends itself to this hypothesis. Idyllic backdrops are used in his studio, as well as intricate costumes at times. A notable example is an entire series of the girls of the Kitchin family, in which the girls were presented in elaborate Oriental costumes or other ethnic garb. ${ }^{4}$ Even the nudes often make key use of a few simple props and backdrops to suggest mythological images of nymphs.

If this was the comfort of mothers whose daughters were photographed by Dodgson, then the fact that most of the mothers and their daughters were fans of Carroll's writing seems quite natural, as it actively establishes this separation of fantasy and reality, reassuring them of the borders between the two. It is all the more appropriate, then, that Dodgson would (as we read in the earlier cited letter to Gertrude Thomas) bait subjects with his reassuringly nonsensical fiction. My use of a hunting metaphor — "bait" — is not unwarranted in this context, as Dodgson himself, in a letter to Mrs. P.A.W. Henderson dated June 21, 1881, employs similar imagery:

I quite hope that picture on your drawing-room table will serve as a sort of "decoy duck" and reveal to you (and through you to me) other 
parents who posses well-made children who have a taste for being taken without the encumbrances of dress. (Letters, v. I, 434)

Such language, most likely, sounds criminally sexual and aggressive to the modern reader. However, at the time there may have been less of a vocabulary available with which to express such concerns. 1883 marked the formation of the Society for the Prevention of Cruelty to Children (SPCC) (Rose, 235). Throughout the next two decades, the SPCC succeeded in passing a large number of bills which, among other things, raised the age of consent (from 14 to 16), enforced stricter child labor restrictions, criminalized the presence of children under 16 in public houses (not out of concern for juvenile temperance, but rather in an effort to combat child prostitution), made domestic abuse of children a criminal offense, made domestic neglect a criminal offense, and culminated in the Incest Act of 1908, in which incest was recognized as a criminal offense. Previous to these efforts, the sexual relations of children and adults had remained underground and generally undocumented. If one were to accuse someone of pedophilic abuse - and keep in mind the difficulty of articulating such things when we lack the legal vocabulary with which to name them - there would have been no simple legal recourse one could have taken against the abuser. ${ }^{5}$ This "golden age" of child legislation reform, however, changed that irrevocably.

As it happens, Charles Dodgson never photographed another nude girl after 1880. Some authors have suggested rumors stopped him, though from his own diaries it seems that Dodgson paid little mind to rumors. Cohen suggests, in Lewis Carroll's Photographs of Nude Children, that he stopped for purely aesthetic reasons, being dissatisfied with the new photographic technology of the "dry plate" as opposed to his own preferred "wet plate." But none have pointed out the growing vocabulary through which relations between child and adult the ultimate collapse of fantasy and reality into what must have been Victorian England's worst nightmare-vision - could more easily and publicly be articulated.

It is in part the inheritance of the SPCC that allows, and even compels, the modern reader to collapse retrospectively the fantasies of Dodgson's photographs into his personal life. It makes little difference that Dodgson, in his lifetime or since his death, has never been accused of sexual abuse or indecencies, not even by his nude child-models; that matters no more than Dodgson's lack of experience with psychedelic drugs concerned Jefferson Airplane. It is in the constructing of Dodgson as a pedophile that modern readers collapse fantasy and disentangle themselves from the perceived repression of the Victorian era.

\section{Conclusion: Towards Our Own Texts}

The desire to impose postmodern sensibilities on the literature and persona of Lewis Carroll, collapsing fantasy and reality as I have outlined, may come from a well-intentioned political goal. At best, it is an active attempt to discard the "innocence" attributed to an era in which dominant culture chose to remain ignorant of its own shortcomings; to reject the imperialist tradition and 
the neat, orderly boxes in which the culture tried to arrange its reality so as to be more easily quantified and conquered; and to show where fantasy and its subordinated constituency bleeds into hegemonic reality, breaking perceived borders and ultimately leading to the reforms and revisions that empowered the current regime. But does this instance of deconstruction really dismantle or challenge the mechanisms of the imperialist regime being rejected? Is it problematic that the same panoptic gaze used to identify racial, sexual and political "deviants" has been adopted in the name of rejecting such oppression?

James Kincaid has suggested, in his book Child-Loving, that the pedophile is "our most important citizen," as it is only through the marking of an Other as morally despicable, then systematically casting them out, that our own moral position can be known (5). Theorist Julia Kristeva identifies this as a "ritual of defilement," a process that is fundamental to human society. Just as, in Alice in Wonderland, rationality is codified by plumbing the depths of nonsense, we tend to understand morality primarily through such dramatic demonstrations of immorality. In fact, in a culture largely dominated by "norms" (a statistical vestige of the $19^{\text {th }}$ century), any deviations beyond the standard are identified as exceptional and mark the limits of normality. Perhaps it is not surprising, then, that the exceptionally adored and the exceptionally reviled are often indistinguishable from moment to moment; our literary giants, our celebrities and our pedophiles may even exist within the same identities.

This is what many have posthumously done - for better or worse - with Lewis Carroll/Charles Dodgson.

Similarly have we constructed celebrities such as Woody Allen and Michael Jackson. These figures have both captured our most fundamental desires and our most active fears; rarely are public reactions so volatile as they have been in response to these child-lovers. In all three of these modern cases, the actual crimes are the not the issue for the culture at large — no more than the modern reader considers Dodgson's apparent celibacy when judging his photography as "immoral." The images of these figures fit our vocabulary of "pedophile" and can therefore serve that purpose in our own defilement rituals.

In these two recent cases, the media responded to the criminal accusations almost immediately, with the implication of guilt based solely on their social position and role as celebrity, even without any real evidence. In both cases the media used the titles of the artists' works to pin their crimes upon their personae. Hence, Woody Allen was pegged with "Crimes and Misdemeanors" and it was asked of Jackson, "Who's Bad?" The use of these artists' works to mark their guilt is a dramatic example of the collapsing between fantasy and reality, completely independent of the legal process.

Once Woody Allen released Manhattan Murder Mystery, which critics applauded as his best work in several years, he was promptly accepted back into the role of film auteur. This illustrates that the viewing public is less concerned with guilt than with the performance of defilement rituals. Similarly, MTV barred Jackson from broadcast within 24 hours of the accusations of sexual abuse being leveled against him. (So much for due process.) However, MTV 
apparently reconsidered in time for the multi-million dollar media event of the HIStory album release. Once these figures may be used for another social function (in this case a capitalistic one), and our Other has shifted elsewhere, they are accepted back openly, and we allow the fantasy to be re-constructed.

I do not claim to know the innocence or guilt of those accused. Nor am I calling for increased empathy for pedophiles. What I am questioning is the effectiveness of establishing norms through defilement rituals, especially when they concern real people whose guilt has not yet been determined, or whose guilt cannot be determined one way or the other, as is the case with Charles Dodgson. Do we create public pedophiles to be despised at the cost of failing to examine the social ills that allowed those public pedophiles to be constructed in the first place? For example, in the journalistic sensation surrounding the murder of JonBenet Ramsey - the 6-year old beauty queen who was raped and killed in her own home - it is clear that the media and the general public suspect the parents themselves of incest, pedophilia and murder. From network television to supermarket tabloids, the Ramsey's have been held up for public humiliation before any legal judgment has been made. But is the public asked to consider the ramifications of the systematic sexualization of this young girl through a series of beauty pageants in her very early life? Do we think very deeply about our own persistent fantasy/reality constructions, finding sexualized images of young girls completely acceptable and even "cute," despite the horror we feel if these fantastic images become reality? In fact, most tabloid presses made use of the young girl's status as a beauty pageant queen as further tragedy in the wake of her untimely death.

To reconsider our act of Othering we need not necessarily reconsider the benefits of pedophilia. What we might do, however, is recognize our own looking-glass, duplicitous image in the construction of childhood as the culmination of desirable qualities - innocence, youth, purity, beauty — and our construction simultaneously of the lover of children (at least in its most provocative manifestations) as the culmination of despicable qualities. It seems to me that the abandonment of the idolization of "innocence" - which has always been a thin disguise for ignorance - would be a possible first step towards the destruction of the hypocrisy. Rather than find sadistic and scopophilic pleasure in Alice's confusion in Wonderland, perhaps we can shatter the fantasy, and see our own reality not unlike Alice's existence in Wonderland - in search of selfawareness and self-knowledge, even at the cost of our own childhood.

\section{Works Cited}

\section{Clarke, Anne. The Real Alice: Lewis Carroll's Dream Child. New York: Stein} and Day, 1982

Carroll, Lewis. The Letters of Lewis Carroll, volumes I \& II. Morton Cohen, ed. New York: Oxford University Press, 1979

Cohen, Morton. "Lewis Carroll and Victorian Morality." In Sexuality and Victorian Literature, ed. Don Richard Cox. Knoxville: University of 
Tennessee Press, 1984

Dyhouse, Carol. Girls Growing Up in Late Victorian and Edwardian England.

London: Routledge and Keagan Paul, Ltd., 1981

Houghton, Walter E. The Victorian Frame of Mind, 1830-1870. New Haven:

Yale University Press, 1959

Kincaid, James. Child-Loving: The Erotic Child and Victorian Culture. New York: Routledge Press, 1992

Phillips, Robert, ed. Aspects of Alice: Lewis Carroll's Dreamchild as Seen Through the Critic's Looking-Glasses. New York: Vanguard Press, 1971

Rose, Lionel. The Erosion of Childhood. New York: Routledge, 1991

Spilka, Mark. "Dickens' Views of Childhood" in Sexuality and Victorian

Literature. Don Cox, ed. Knoxville, University of Tennessee Press, 1984

Wallace, Richard. The Agony of Lewis Carroll. Melrose, MA: Gemini Press, 1990

Wullschläger, Jackie. Inventing Wonderland: The Lives and Fantasies of Lewis Carroll, Edward Lear, J.M. Barrie, Kenneth Grahame and A.A. Milne. New York: The Free Press, 1995

\section{Notes}

${ }^{1}$ I will continue to use both Dodgson's given name and his assumed literary name, Lewis Carroll, alternately, as appropriate to whichever persona I may be referring.

${ }^{2}$ Much of this discussion comes out of my own research on LSD and American visual culture, yet to be published.

${ }^{3}$ Actually, the family of Dodgson has withheld some forty percent of his diaries from publication or any type of public perusal. This date is unique only in its clear importance to the relationship of Alice Liddell and Dodgson.

${ }^{4}$ Cohen, Morton, ed. Lewis Carroll and the Kitchins. New York: The Lewis Carroll Society of North America, 1980.

${ }^{5}$ I do not mean to suggest that child sexual abuse was simply tolerated previous to the 1880's. In England, the ever-elastic sodomy law would most likely have been employed to persecute offenders that came to public attention. But such a situation still lacks an expediency that the new legislation could afford. Consider the difficulty, for example, that a contemporary female has with dealing with a "stalker." While I'm sure that no lawmaker feels that it is appropriate to systematically terrorize a woman, the legalities of actually bringing such actions to justice are infinitely complicated by a lack of a criminal vocabulary for the action. 